\title{
AS CONTRIBUIÇÕES DA TERMODINÂMICA AO PENSAMENTO ECONÔMICO
}

\author{
Tiago Soares Barcelos ${ }^{*}$ \\ Pedro Luiz Teixeira de Camargo* \\ Valmir Percival Guimarães ${ }^{* * *}$ \\ Loyslene de Freitas Mota***t
}

Resumo: As Ciências Econômicas como um todo e a Economia Ecológica em especial, tem nas definições de temperatura, calor, energia, trabalho e entropia alguns dos seus principais conceitos epistemológicos. Doravante, trabalhos teleológicos capazes de abordar historicamente tais definições, bem como seu uso nesse campo científico são raros, sendo por isso importantes. Dessa forma, propõe nesse artigo discutir, através de uma revisão bibliográfica profunda, as contribuições da termodinâmica ao pensamento econômico. Como resultado, é possível apontar que Brandão (2004); Pádua, et al (2008); Cechin e Veiga (2010); Castro e Ferracioli (2012); Georgescu-Roegen (2012) e Daly e Farley (2016) são os principais autores que relacionam a temática econômica e termodinâmica. Como conclusão, é possível afirmar que são necessários mais estudos de revisão historiográfica dentro da Economia Ecológica, sendo indicados mais trabalhos similares a esse que sejam capazes de oferecer uma abordagem acerca da epistemologia dos termos mais usados nessa área científica.

Palavras-chave: Economia Ecológica; Epistemologia; Entropia

\footnotetext{
* Doutorado em Geografia Humana - USP.

${ }^{* *}$ Doutor em Ciências Naturais - UFOP.

${ }^{* * *}$ Doutor em Teoria da Literatura e Literatura Comparada - UERJ.

**** Bacharel em Engenharia Civil - Pitágoras.
} 


\begin{abstract}
Economic Sciences as a whole and Ecological Economics in particular, have in their definitions of temperature, heat, energy, work and entropy some of their main epistemological concepts. Henceforth, teleological studies capable of historically addressing such definitions, as well as their use in this scientific field, are rare and are therefore important. Thus, this article proposes to discuss, through a thorough bibliographic review, the contributions of thermodynamics to economic thought. As a result, it is possible to point out that Brandão (2004); Padua, et al (2008); Cechin and Veiga (2010); Castro and Ferracioli (2012); Georgescu-Roegen (2012) and Daly and Farley (2016) are the main authors who relate the economic and thermodynamic theme. As a conclusion, it is possible to affirm that more studies of historiographical revision are needed within Ecological Economics, indicating more works similar to this one that are capable of offering an approach about the epistemology of the most used terms in this scientific area.
\end{abstract}

Keywords: Ecological Economy; Epistemology; Entropy

\title{
Introdução
}

A termodinâmica clássica ou termodinâmica de equilíbrio, conforme Pádua, et al (2008, p. 58), é "[...] uma das poucas áreas bem consolidadas da física, sintetizada por uma estrutura de conhecimento bem definida e autoconsciente". Sua essência está em uma estrutura teórica que busca compreender conjuntos e leis naturais que governam os sistemas físicos. Para estes autores as observações seguem duas alternativas:

[...]aproximação histórica, que faz um estreito paralelo entre a evolução cronológica dos conceitos corretos e dos falsos juizos e, a aproximação postulatória, na qual são formulados postulados que não são demonstrados a priori, mas que podem ter suas veracidades confirmadas a posteriori. Há méritos e desvantagens em cada uma dessas aproximações (PADUA, et al, 2008, p. 58)

A capacidade de transformar o seu meio ambiente conforme suas necessidades difere o homem dos animais. Além disso, a espécie humana compreende os fenômenos naturais por meio de várias ciências, em um 
contínuo e gradual processo de aprendizagem. Por intermédio deste processo, o homem passa a utilizar do conhecimento para transformar seu ambiente em energia, a fim de satisfazer suas necessidades básicas.

Conforme Condie (2005), o estudo da transformação de energia, é chamado de termodinâmica, sendo esse estudo uma ciência hierárquica os conceitos mais avançados nesse caso, presumem o conhecimento dos conceitos mais básicos.

Portanto, a relação entre fontes de calor e outras formas de energia, exige o entendimento de alguns conceitos básicos e fundamentais para estruturação dos princípios termodinâmicos, que são: temperatura, calor, energia, trabalho e entropia. E é sobre isso que vai se dar este artigo.

Portanto, através da revisão bibliográfica, propõe-se, nesse trabalho, debater acerca das contribuições da termodinâmica no pensamento econômico ocidental.

As fontes de pesquisa utilizadas foram sites, livros e obras especializadas acerca do tema, que ainda é pouco explorado dentro da Ciências Econômicas como um todo.

\section{Desenvolvimento}

Halliday e Resnick (2012, p. 184), tem como ponto de partida o conceito de temperatura, estando entre uma das sete grandezas fundamentais do sistema internacional de unidades (SI), além disso, os autores apresentam: o comprimento, a massa, o tempo, a intensidade de corrente elétrica, a quantidade de matéria e por fim, a intensidade luminosa. Para os físicos, a escala ideal é a Kelvin (K), principalmente para medir a temperatura, assim, surge a lei zero da termodinâmica.

Por outro lado, Pádua, et al (2008), afirma a importância da temperatura para a primeira e segunda lei da termodinâmica. Todavia, a lei zero surgiu apenas na década de 1930 e está baseada no equilíbrio térmico. Isso é devido a temperatura ser a principal grandeza da termodinâmica: "[...] esta lei, naturalmente deveria preceder as duas leis já existentes”, sendo ela chamada originalmente por Fowler e Guggenhein, de lei zero da termodinâmica (PÁDUA, 2008, p. 74). 
Ainda Pádua, et al, (2008 p. 74), reforçam que se "[...] dois sistemas termodinâmicos estão em equilíbrio térmico com um terceiro sistema, estão em equilíbrio entre si". Em outros termos, continuam, a lei zero diz que todo corpo possui uma propriedade chamada de temperatura, assim, dois corpos, quando se encontram em equilíbrio térmico, apresentam temperaturas iguais. Desse modo, os termos pertinentes a lei zero são o equilíbrio e o equilíbrio térmico.

Contudo, ainda para Pádua, et al (2008, p. 74), no sentido macroscópico, o equilíbrio consiste em um sistema termodinâmico em que as suas variáveis macroscópicas de estado são constantes no tempo e uniformes por meio de todo o sistema. Já o equilíbrio térmico, são dois sistemas termodinâmicos, ou seja: "[...] quando postos em contato por meio de uma parede diatérmica, suas variáveis de estado não se alteram. Dois sistemas em equilíbrio térmico têm a mesma temperatura" (PÁDUA, et al, 2008, p. 74).

Essas variações de temperatura, a séculos vêm sendo utilizadas pelo homem na conversão de calor e energia para gerar o trabalho. Pádua, et al (2008, p. 67), salientam que no século XVII "[...] haviam duas hipóteses acerca da natureza do calor". A primeira, conhecida como teoria do calórico, afirmava que o calor era uma substância, sendo Galileu um dos adeptos a ela. Ou seja, "[...] o calor era considerado um fluido sutil que preenchia o interior dos corpos" (PADUA, et al, 2008, p. 68).

Já a segunda hipótese, aceita apenas no século XIX, é conhecida como teoria mecânica do calor, tendo sido proposta inicialmente por Bacon, em 1620 e reforçada por Hooke (1665), Newton (1704) e Bernoulli (1738), esta teoria considera que “[...] o calor é uma 'vibração' dos átomos que compunham a matéria" (PADUA, et al, 2008, p. 68).

É por meio do calor que se gera energia. A energia está ligada a capacidade de produção de movimento, ou ação que por sua vez pode ser manifestada de várias formas. Levando-se em consideração o princípio de Lavoisier $^{1}$, a energia não pode surgir do nada e nem pode ser destruída, sendo que a única possibilidade deste fenômeno se modificar é por meio da transformação.

Dessa forma, consideramos que existem várias formas de energia, como a cinética, a potencial, a térmica, a química, a solar, a eólica e por

${ }^{1}$ O princípio de Lavoisier, ou lei de Lavoisier, deriva do trabalho do químico francês Antoine Laurent Lavoisier (1743-1794), correspondendo à lei de conservação das massas, derivando a celebre frase "na natureza nada se cria, nada se perde, tudo se transforma". 
fim, a nuclear, que dado ao escopo do presente trabalho, não serão abordadas. Além disso, observamos que a energia tende a se transformar em trabalho. A física é a relação entre força e deslocamento, e se não há deslocamento, não há trabalho, sendo este compreendido, pelo senso comum, como produto da força pela distância. Assim, em termos físicos, esta definição é suficiente para este trabalho pois, quando se pensa na relação com a economia, ela tem outra conotação (CASTRO; FERRACIOLO, 2012).

A energia pode assumir um número grande de formas diferentes. Do ponto de vista prático, energia é a capacidade de se realizar trabalho, mas do ponto de vista científico, energia é uma ideia abstrata. Acredita-se que a energia não pode ser criada nem destruída, mas simplesmente mudar de uma forma para outra. Esse é um princípio básico da física sendo até então exato. Estabelece assim uma grandeza abstrata, que é chamada de energia, cujo valor numérico permanece constante nas várias mudanças que ocorrem na Natureza.

Percebemos que a termodinâmica é a ciência que analisa as transformações de energia por meio das leis naturais. Abordado os principais conceitos e a lei zero, avançamos nesse momento para a primeira e segunda leis da termodinâmica, que são muito úteis para a Economia Ecológica. Assim, para Castro e Ferracioli (2012), a primeira lei visa estabelecer a conservação de energia em qualquer processo da natureza, tendo como base a compreensão do calor e o trabalho. Já a segunda lei determina a assimetria fundamental da natureza.

Daly e Farley (2016), fazem um cronograma histórico acerca da termodinâmica. Com o advento da revolução industrial os cientistas ficaram intrigados com a possibilidade de uma máquina de movimento perpétuo, sendo alimentada pelo próprio calor. Com o passar do tempo houve a contribuição de vários cientistas, como Mayer e Helmholtz que demonstraram que a energia não poderia ser criada ou destruída. Joule realizando experimentos acabou demonstrando que "[...] a energia e o trabalho são equivalentes" (DALY; FARLEY, 2016, p. 110). Clausius acabou reconhecendo que haviam "dois princípios relacionados operando, que vieram a ser conhecidas como primeira e segunda leis da termodinâmica" (DALY; FARLEY, 2016, p. 110).

Dessa forma, Daly e Farley (2016, p. 110) reforçam que "[...] todos os tipos de energia são transformados gradualmente em calor, e o calor, no fim do processo, torna-se tão dissipado que a humanidade já não pode 
mais usá-lo". Desta maneira, a primeira lei se refere à quantidade e a segunda à qualidade. Vale ressaltar que nos conceitos aqui abordados, a questão entropia não foi trabalhada, sendo parte fundamental do trabalho e presente a partir de agora de forma mais profunda.

A entropia está ligada diretamente às ideias de ordem e desordem dado a um conjunto de probabilidades de ocorrência. É assim que a entropia de um sistema está relacionada à sua capacidade de produzir trabalho. A questão que Castro e Ferraciolo (2012, p. 3), apresentam sobre a entropia é "[...] porque nunca observamos o processo inverso espontâneo em alguns fenômenos? ". Estes autores consideram que o processo no sentido contrário de alguns fenômenos resultaria em "[...] uma ordenação no movimento aleatório das moléculas", originando assim uma "[...] conversão de energia interna em trabalho" (CASTRO; FERRACIOLO, 2012, p. 3).

Diante deste contexto, tanto a economia ambiental quanto a economia ecológica fazem uso dos princípios da física para as suas análises, nas quais, conforme Moraes (2009), quando se aplicam os conceitos das leis termodinâmicas, fica claro que inevitavelmente todos os recursos extraídos do meio ambiente retornarão como resíduos.

O crescimento não ocorre no vazio, podendo ser econômico ou antieconômico (CECHIN; VEIGA, 2010). Veiga e Zatz (2008), destacaram que a lei da entropia é inexorável para o sistema econômico, pois consideram que as sociedades humanas "[...] transformam obrigatoriamente energia utilizável em energia não-utilizável, seja qual for o tipo de energia”. Cechin e Veiga (2010, p. 42) reforçam que pela termodinâmica, ao se produzir bens finais, a quantidade de matéria e energia incorporadas na produção é menor que aquela contida no início do processo. Isso significa que parte da energia e matéria de baixa entropia se transforma em resíduos sem valor econômico. Logo, não é possivel uma eficiência total, como Carnot procurava com a sua física econômica. Entretanto, Cechin e Veiga (2010, p. 42) afirmam que não se pode negar que "[...] os avanços na tecnologia de produção significam menos desperdício, com maior proporção de material e energia de baixa entropia incorporada aos bens finais".

Martinez-Alier (2007), destacou que a formulação fundamental da ecologia se refere a energia e materiais, estando presentes na física e biologia. Dessa forma, para esse autor, o saber cientifico da ecologia está relacionado com diversas ciências, sendo importante o conceito da entropia advindo da termodinâmica. 
Este conceito é reforçado por Montibeller (1999, p. 87), afirmando que a "[...] entropia é a medida da quantidade de desordem de um sistema". Altvater (1995, p. 45) explica que as transformações entre matéria e energia possui dois estados principais, o primeiro, de baixa entropia - ou sintropia -, tem como característica os estados de elevada ordem e concentração. Já para aqueles estados de alta entropia, características de desordem e dissipação. É importante ressaltar que para Enriquez (2007, p. 69), Altvater rejeita a possibilidade do desenvolvimento sustentável, estando para ele mais focado na "[...] eficácia ecológica com justiça distributiva e eficiência econômica com base na alta produtividade do trabalho".

Para Georgescu-Roegen (1980, p. 51), a matéria-energia está dentro dos processos econômicos no estado de baixa entropia, no qual, ao final do ciclo, são convertidos em estados de alta entropia. Trata-se assim, conforme Cavalcanti (2017, p. 63), de um fluxo unidirecional "[...] que começa com recursos e termina como lixo", sendo batizado em: fluxo entrópico (Georgescu-Roegen), throughput (Kenneth Boulding) ou transumo por Osório Viana (CAVALCANTI, 2017, p. 63). Surge assim o metabolismo social da Natureza, que pode ser observado na Figura 1.

Figura 1 - Representação do metabolismo social da Natureza

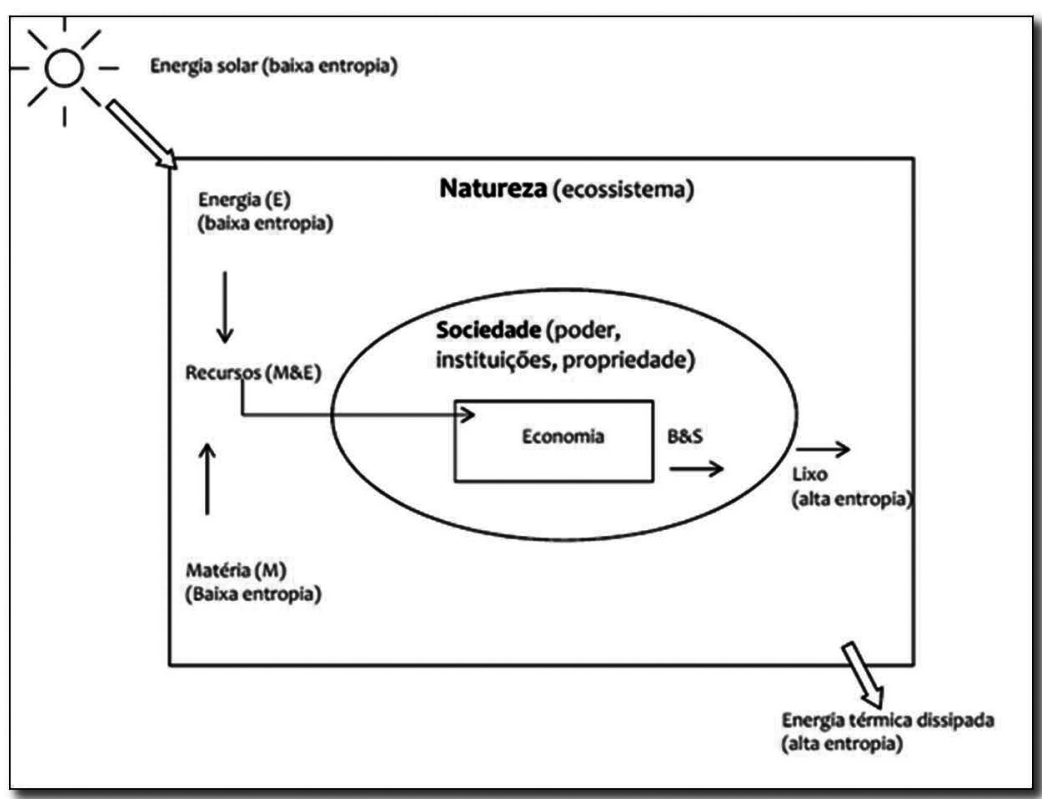

Fonte: Cavalcanti (2017, p. 64). 
A energia solar de baixa entropia nutre a Natureza (ecossistemas), que nos oferecem recursos. Esses recursos vêm da junção das matérias e energia de baixa entropia, que são utilizadas pela sociedade, girando assim a economia. Após esse processo, estes recursos se transformam em bens e serviços e ao final do ciclo de vida, são transformados em resíduos/rejeitos (alta entropia), tendo como saída uma energia térmica dissipada (alta entropia).

Observamos assim que o crescimento é uma variável de suma importância para a nossa compreensão, pois está relacionada diretamente à eficiência ecológica. Com base nesse pensamento "[...] os economistas ecológicos sempre perguntam se o crescimento extra compensa o sacrificio adicional que isto implica" (DALY; FARLEY, 2016, p. 47).

Assim, devemos entender que a "lei da entropia diz que a energia e a matéria no universo movem-se inexoravelmente para um estado menos ordenado (menos útil). Um fluxo entrópico é, simplesmente, um fluxo no qual a matéria e a energia se tornam menos úteis" (DALY; FARLEY, 2016, p. 65).

Conforme observamos na Figura 1, a energia não pode ser criada ou destruída, sendo que o seu montante é sempre constante, na perspectiva temporal humana dentro do nosso espaço geográfico. Essa é a afirmação da Primeira Lei da Termodinâmica, na qual Condie (2005), percebe que mesmo se o total de energia no universo for constante, as transformações de energia na vida que estamos discutindo, certamente poderão afetar a proporção relativa de energia disponível nas formas que esses organismos vivos irão por sua vez, achar úteis.

Esta situação surge não dos defeitos inerentes nas biomoléculas envolvidas nas transformações de energia, mas da natureza e do universo em si. Cechin e Veiga (2010, p. 36), corroboram que a lei da conservação da energia, ou primeira lei da termodinâmica, é sustentada dentro de um sistema isolado (universo) e que "[...] não há troca de matéria nem energia com o meio", sendo esta quantidade sempre constante. Esses autores reforçam que, "[...] não há criação ou destruição de energia, mas apenas transformação de uma forma em outra", e que "[...] nenhuma outra lei da física distingue o passado do futuro" (CECHIN; VEIGA, 2010, p. 36).

Thomas e Callan (2012), inclui a natureza ao modelo clássico do fluxo circular, fazendo o paralelo entre as famílias, empresas, mercados produti- 
vos, mercado de fatores. Dentro da ótica da primeira lei da termodinâmica no balanço de matérias, isto significa que, em longo prazo, "[...] o fluxo de materiais e de energia extraídos da natureza, em forma de consumo e produção, pode ser igual ao fluxo de resíduos gerados que vão destas atividades de volta para o ecossistema", ou seja, nada é perdido dentro deste processo (THOMAS, 2012, p. 16). Esses resíduos podem assumir diversas formas, como: monóxido de carbono, lixo urbano, lixo industrial, poluição dos lagos e rios, entre outras.

Para Cavalcanti (2010) o sistema econômico e a leis da termodinâmica são indicativos que o sistema econômico tem um aparelho digestivo, além do circulatório, imaginado pela economia tradicional. Devemos compreender que toda transformação implicada pelo homem à natureza gera resíduos que a degradam (a depender da escala), por sua vez, essa possui uma resiliência incompativel com os meios econômicos, sendo assim um sistema fechado.

Um sistema está em qualquer tempo num certo estado termodinâmico ou em condição de existência (em que os tipos de moléculas estão presentes numa quantidade, temperatura, pressão, etc.). Um sistema é dito fechado se este puder trocar calor com os arredores. Isto é, o limite de um sistema fechado é impermeável para a matéria. Outro exemplo de um sistema fechado, é a própria Terra. Nosso planeta, continuamente recebe energia radiante do sol e desprende calor, mas porque a Terra não é nem muito pesada nem muito leve, a troca do planeta praticamente não tem importância para os arredores (CONDIE, 2005).

A Segunda Lei da Termodinâmica corresponde à capacidade limitada da natureza em converter matéria e energia, em outras palavras, conforme ocorre a conversão de energia, parte dela torna se inutilizável. Destarte, caso a energia ainda exista, ela não estaria disponível para outros processos humanos, o que torna a economia um subsistema de um sistema finito - a Terra.

Cechin e Pacini (2012, p. 124), ressaltam a armadilha métrica monetária, na qual tanto a redução dos impactos ecológicos, quanto dos setores econômicos (valores monetários) faz com que se esqueça, por exemplo, de que energia é "[...] um dos fatores mais críticos na história da humanidade". Esses autores ainda ressaltam que "os limites biofísicos da renovação 
dos recursos naturais e da assimilação dos resíduos sejam mascarados por não afetarem o PIB de maneira significativa" (CECHIN; PACINI, 2012, p. 124). Sobre isso, há uma vasta literatura a respeito das falhas métricas entre a contabilidade social e o meio ambiente, não entrando no escopo do presente trabalho.

Assim, a segunda lei da termodinâmica, nada mais é que a lei da entropia. Daly e Farley (2016), analisam a questão da reciclagem, que nunca chega a $100 \%$. Destarte, para esses autores, a energia não é sempre reciclável. Não é fisicamente impossível, todavia há sempre um desperdício econômico.

Cechin e Veiga (2010, p. 42) complementam afirmando que dentro da segunda lei da termodinâmica "[...] nem toda energia pode ser transformada em trabalho, pois uma parte sempre se dissipa em calor. E energia dissipada não pode mais ser utilizada". Portanto, considerando o fluxo circular da renda, os economistas convencionais esqueceram o fluxo metabólico real que envolve estas variáveis indissociáveis a compreensão dialética entre natureza e sociedade.

Georgescu-Roegen (2012, p. 83), apresenta uma observação singular com relação a segunda lei da termodinâmica, pois é "[...] a única lei física que reconhece que o próprio universo material está sujeito a uma mudança qualitativa irreversível, a um processo evolutivo". Dessa forma, Clausius cunha este termo a partir de dois componentes gregos, sendo o prefixo thermo (calor) e dýnamis (força), adotando um sentido de transformação e evolução. Quando se pensa em economia, percebemos que ela é, provavelmente, a lei mais relevante e coerente, pois, sabemos que as leis mecânicas não explicam de forma satisfatória o metabolismo ecológico que a economia causa, sobretudo, para com os ecossistemas.

Observamos que a física não vem sendo utilizada pelos economistas convencionais. A sua métrica é do crescimento eterno e ela não se justifica. Nesse sentido, a economia ecológica vem travando críticas aos economistas convencionais, principalmente a respeito destes assuntos, afinal, em termos politicos, existe uma capacidade para o suporte que necessitam de limitadores de escala. Dado ao fenômeno da escassez, a energia assim como os recursos naturais possuem custos ocultos, que não são revertidos aos preços. 
É importante notar que, conforme Loyola (1997), que as formas como as leis da termodinâmica são tratadas pela economia ambiental e ecológica geram proposições diferentes como medidas políticas, em especial quando se pensa em solucionar os problemas relacionados ao meio ambiente.

Brandão (2004) considera que as relações entre a economia e a termodinâmica clássica ocorrem desde o seu nascimento, pois o problema com o qual Carnot se debruçava estava ligada à natureza econômica. Seu trabalho buscava determinar as melhores condições sob a forma do trabalho mecânico. Logo, afirma o autor, "[...] a termodinâmica seria, então, a física do valor econômico, que utiliza um enfoque holístico e reconhece a noção dos limites físicos" (BRANDÃO, 2004, p. 6).

Para sintetizar o que foi exposto até o momento considerando as leis da termodinâmica, tendo como base as interpretações de Haddad (2017), vejamos:

$1^{\circ}$ lei da termodinâmica - (conservação de matéria e energia) a retirada ou a reposição de matéria ou energia no ecossistema deve desestruturar o funcionamento desse sistema, independentemente do uso que se faça da matéria ou da energia extraída e também, independentemente da degradação qualitativa da matéria ou da energia realocada;

$2^{\circ}$ lei da termodinâmica - (lei da entropia) garante que a matéria e a energia extraídas de modo qualitativo, diferente da matéria e da energia que são reinseridas; matérias de baixa entropia, nesse caso, são retiradas e os resíduos de alta entropia são retornados.

Outro ponto importante abordado por Daly e Farley (2016, p. 66), é a utilização de um erro batizado por Whitehead de falácia da concretude deslocada. Esse tipo de erro se baseia em modelos que são construídos a partir da abstração. Assim, conforme os autores, a economia é considerada isolada do meio ambiente, em que "[...] não pode trazer qualquer luz sobre a relação da economia com o meio ambiente". Assim:

[...] querendo designar o erro de confundir o mapa com o território, o erro de tratar um modelo abstrato, construído com o propósito de compreender um aspecto da realidade como se fosse adequado para compreender tudo, ou coisas totalmente diferentes, coisas que se tornaram abstratas com a realização do modelo. Whitehead não era inimigo do 
pensamento abstrato. Ele dizia que não podemos pensar sem abstração. O poder do pensamento abstrato tem um custo. A falácia da concretude deslocada é esquecermos destes custos (DALY; FARLEY, 2016, p. 66).

Este tipo de erro, conforme Daly e Farley (2016), não se limita apenas aos economistas tradicionais, afinal, outros grandes como Marx e Malthus já o cometeram. Em sua teoria, reforçam os autores, Marx (1978) defende que o trabalho era a fonte de todo valor, com isso, ele nega o papel importante no funcionamento da natureza e na criação de valor.

Para Malthus, quando o excesso populacional era derivado da capacidade limitada dos recursos naturais, esta foi “[...] igualmente uma causa independente da pobreza, e que a revolução social não poderia eliminar (totalmente) a pobreza" (DALY; FARLEY, 2016, p. 70).

Brandão (2004), utilizando o trabalho de Fischer, tenta estabelecer os limites das relações existentes entre a física e a economia, conforme a Tabela 1 .

Tabela 1 - Resumo das diferenças percebidas entre a física e economia

\begin{tabular}{ll}
\hline \multicolumn{1}{c}{ Física } & \multicolumn{1}{c}{ Economia } \\
\hline Partícula & Individuo \\
Espaço & Bens \\
Força & Utilidade ou Desutilidade marginal \\
Trabalho & Desutilidade \\
Energia & Utilidade \\
Trabalho da energia = Força por espaço & Utilidade = utilidade marginal por bens \\
& e serviços \\
Força é um vetor & Equilibrio marginal é um vetor \\
Equilibrio de energia neta é máximo as & Equilibrio se produz quando o \\
forças sobre os eixos é igual a zero & beneficio marginal é igual a zero \\
Energia cinética & Total de gasto \\
Movimento & Unidade incremental dos bens \\
Conservação de energia & Conservação de utilidade mais renda \\
\hline
\end{tabular}

Fonte: Fischer, apud Brandão (2004, p. 6). 
Até o momento analisamos a lei zero e a primeira e a segunda leis da termodinâmica, assim, consideramos importante destacar outras duas teorias. Nesse caso, a terceira e a quarta lei da termodinâmica, conforme Daly e Farley (2016, p. 111) "[...] a entropia de qualquer elemento puro, perfeitamente cristalino ou composto de zero absoluto $(0 \mathrm{~K})$ é igual a zero", sendo que este princípio não é relevante para uma análise econômica.

Os autores destacam que quanto a quarta lei termodinâmica proposta por Georgescu-Roegen, esta se baseia em responder a seguinte questão: importa como a energia obedece às leis da termodinâmica? A equação de Einstein, $\mathrm{E}=\mathrm{mc}^{2}$, estabelece que " $[\ldots]$ a equivalência entre a matéria e a energia e, portanto, o fato de que a primeira lei se aplica à matéria bem como à energia" (DALY; FARLEY, 2016, p. 111).

Essa é também uma das bases de sustentação da lei da entropia e nesse sentido, Georgescu-Roegen argumenta que a lei da entropia deve ser aplicada à matéria, propondo que este princípio fosse reconhecido como a quarta lei da termodinâmica (DALY; FARLEY, 2016). Todavia, conforme Martinez-Alier (2015), Georgescu-Roegen buscou glorificar, sem êxito, a quarta lei da termodinâmica...

\section{Considerações Finais}

Para concluir, é importante salientar, que o trabalho cumpriu sua proposta de trazer à tona o debate epistemológico acerca das principais contribuições da termodinâmica ao pensamento econômico. Definições como temperatura, calor, energia, trabalho, entropia, entre outros foram abordados de maneira profunda explicando a lógica e os motivos de seu uso dentro dessa escola econômica.

Dessa forma, buscar compreender a capacidade de suporte ecossistêmico, principalmente, dentro do subsistema econômico que leve em consideração as leis termodinâmicas e as questões ecológicas parece estar na ordem do dia, sendo importante mais estudos acerca desta temática.

Talvez seja esta a grande limitação dos trabalhos que se propõem a mergulhar no debate teleológico, a dificuldade de mostrar a importância desse estudo para o desenvolvimento científico, sendo importante que se 
pense cada vez mais na importância de estudos históricos acerca das origens das principais terminologias usadas na Economia Ecológica.

Por último, e não menos importante, indica-se que se pense em mais incentivos para o desenvolvimento desse campo de estudo dentro das ciências econômicas como um todo, pois é através do estudo e compreensão do passado que se pode melhorar o presente buscando achar as soluções ecológico-econômicas no tempo futuro.

\section{Referências}

ALTVATER, Elmar. O preço da riqueza: pilhagem ambiental e a nova (des) ordem mundial. Tradução de Wolfgang Leo Maar. São Paulo: Editora da Universidade Estadual Paulista, 1995.

CASTRO, Reginaldo; FARRICIOLI, Laércio. Segunda lei da termodinâmica: um estudo de seu entendimento por professores de ensino médio, 2012.

CAVALCANTI, Clóvis. Concepções da economia ecológica: suas relações com a economia dominante e a economia ambiental. Estudos avançados 24 (68), p. 53-67, 2010.

CAVALCANTI, Clóvis. Economia ecológica: uma possivel referência para o desenho de sistemas humanos realmente sustentáveis. Redes - Santa Cruz do Sul: Universidade de Santa Cruz do Sul, v. 22, n. 2, maio-agosto, p. 56692017.

CECHIN, Andrei Domingues; VEIGA, José Eli da. O fundamento central da economia ecológica. In: MAY, Peter H (Org). Economia do meio ambiente: teoria e prática. 2.ed. Rio de Janeiro: Elsevier, p. 33-48, 2010 a.

CECHIN, Andrei; PACINI, Henrique. Economia verde: por que o otimismo deve ser aliado ao ceticismo da razão. Estudos avançados. São Paulo, v. 26, n. 74, p. 121-135, 2012.

CONDIE, Kent. C. Earth as na evolving planetary system. Elsevier, 2005.

DALY, Herman; FARLEY, Joshua. Economia ecológica. São Paulo: Annablume Cidadania e Mio Ambiente, 2016.

ENRIQUEZ, M. A. R. S. Maldição ou Dádiva? Os dilemas do desenvolvimento sustentável a partir de uma base mineira. Tese de Doutorado. Universidade de Brasília. Brasília, DF, 2007. 
GEORGESCU-ROEGEN, Nicholas. The entropy law and the economic problem. In DALY, Herman (org.). Economics, Ecology, Ethics. Essays toward a Steady-State Economy. São Francisco: Freeman, p. 48-60, 1980.

HADDAD, Paulo. Economia ecológica e ecologia integral. Edição Kindle. Amazon, 2017.

HALLIDAY, David; RESNICK, Robert. Fundamentos da física: gravitação, ondas e termodinâmica. São Paulo/SP; 9. Ed.; LTC, 2012.

LOYOLA, R. A economia ambiental e a economia ecológica: uma discussão teórica. Anais... do II Encontro da Sociedade Brasileira de Economia Ecológica. São Paulo/ SP, 1997.

MARTÍNEZ, J.M. Economia ecológica. International encyclopedia of the social and behavioral science. Tradução: Joseph S. Weiss e Clóvis Cavalcanti, 2015.

MARTÍNEZ-ALIER, J. O ecologismo dos pobres: conflitos ambientais e linguagens de valoração. São Paulo: Contexto, 2007.

MARX, K. O Capital. O Capital [Livro I]. São Paulo: Ciências Humanas. 1978.

MONTIBELLER FILHO, Gilberto. O Mito do Desenvolvimento Sustentável. Tese de Doutorado (Ciências Humanas/Sociedade e Meio Ambiente). Florianopoles, UFSC, 1999.

MORAES, Orizimbo José de Moraes. Economia Ambiental: instrumentos econômicos para o desenvolvimento sustentável. São Paulo: Centauro, 2009.

PÁDUA, Antônio Brás; et al. Termodinâmica clássica ou termodinâmica de equilíbrio: aspectos conceituais básicos. Ciências Exatas e da Terra, Londrina, v. 29, n. 1, p. 57-84, jan/jun. 2008.

THOMAS, Janet M; CALLAN, Scott. Economia ambiental: fundamentos, políticas e aplicações. São Paulo: Cengage Learning, 2012.

VEIGA, José Eli da.; ZATZ, Lia. Desenvolvimento sustentável: que bicho é esse? São Paulo: editora autores associados, 2008. 